\title{
Temperature and Precipitation Effects on Birth Rates in Sub-Saharan Africa
}

Brian C. Thiede*, The Pennsylvania State University, Sara Ronnkvist, The University of Wisconsin-Madison, Anna Armao, Ohio State University, Demi Amideneau, Florida International University, Katrina Burka, The Pennsylvania State University

August 17, 2020

*Corresponding author: 111A Armsby Building, The Pennsylvania State University, University Park, PA 16802; Phone: 814-865-2561; E-mail: bct11@ psu.edu

\section{Acknowledgements}

We acknowledge the support of a research experience for undergraduates (REU) sponsored by The Pennsylvania State University and Project Drawdown during the summer of 2019. Thiede also acknowledges assistance provided by the Population Research Institute at Penn State University, which is supported by an infrastructure grant from the Eunice Kennedy Shriver National Institute of Child Health and Human Development (P2CHD041025). 


\begin{abstract}
Previous literature on climate change and human population dynamics has mainly focused on how population growth affects greenhouse gas emissions. Much less research has analyzed how climatic variability influences the size of human populations, despite reasonable expectations of such effects. Evidence of climate-fertility linkages, or lack thereof, is needed to refine understandings of adaptive behaviors. It is also needed to refine models of the demographic drivers of greenhouse gas emissions, which tend to assume climatic changes will not feedback to impact population dynamics. We test this relationship using birth histories from 23 sub-Saharan African countries and high-resolution climate data. Our analyses show that exposure to climatic variability is associated with fertility in sub-Saharan Africa, albeit in complex ways. Women exposed to hot-and-dry spells experience significant reductions in the annual probability of fertility, while exposure to above-average temperatures and precipitation is associated with increased fertility over baseline. These associations vary between demographic and geographic groups, revealing important differences in vulnerability and adaptive behavior.
\end{abstract}

\title{
Introduction
}

The links between greenhouse gas emissions and human population growth have been of interest to many scientists and policymakers (Bongaarts 1992; Lutz 2017). However, prior work on this topic has focused largely on understanding whether and how changes in the size and composition of human populations influence greenhouse gas emissions (Bongaarts \& O’Neill 2018; O’Neill et al. 2010; O'Neill et al. 2012). Less attention has been given to the effects of climatic changes on human fertility (Eissler et al. 2019; Grace 2017; Sellers \& Gray 2019), which is the primary driver of population growth (and decline) across the world. Evidence of climate-fertility links —or lack thereof - can improve our understanding of climate adaptation behaviors. It can also refine models of greenhouse gas emissions by accounting for the dynamic relationship between population growth and emissions. We address this issue here by estimating the effects of climatic variability on birth rates across Saharan Africa. ${ }^{1}$

Changes in reproductive behavior are among the demographic adaptations that households may employ to cope with the impacts of climatic variability. This relationship may be driven by multiple pathways. Climate shocks may change household income (Hertel et al. 2010) and in doing so alter the relative costs of children and women's ability to regulate fertility through access to

\footnotetext{
${ }^{1}$ We model the effects of short-term climatic variability-i.e., the deviation of temperatures and precipitation during three-year intervals from the long-term mean - rather than longer-term changes in climate. Estimates of the effects of short-term variability can be used to form plausible expectations about the consequences of longer-term climatic change, and indeed our approach is ubiquitous in the social science literature on climate change impacts (Gray \& Wise 2016; Mueller et al. 2014; Nawrotzki et al. 2015).
} 
contraceptives (Alam \& Pörtner 2018; McKelvey et al. 2012; Sellers \& Gray 2019). Climateinduced income shocks may also influence intra-household dynamics, such as conflict between spouses (Hidrobo \& Fernald 2013; Hidrobo et al. 2016), in ways that alter reproductive behavior. Relatedly, environment-induced changes in migration may affect the likelihood of spousal separation (Hunter et al. 2015), which is inversely associated with fertility rates (Agadjanian et al. 2011). Fertility rates can be expected to decline in cases where climatic variability increases outmigration (Mueller et al. 2014), with the opposite true when environmental changes reduce mobility (Gray \& Wise 2016). Additionally, climate-induced changes in health and mortality risk may influence birth rates by affecting the likelihood of conception and fetal survival (Davenport et al. 2020). If such environmental changes significantly affect rates of infant mortality, they may also influence fertility by spurring replacement (or insurance) effects in which women have additional children to replace recently-deceased children (or insure against anticipated deaths) (Nobles et al. 2015).

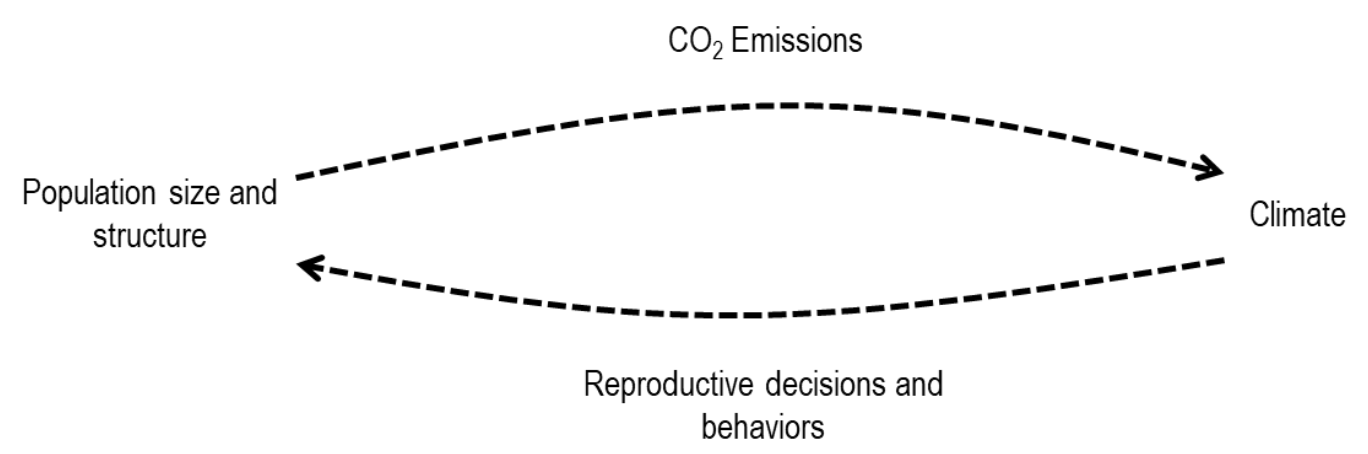

Figure 1: Hypothesized feedback between population and climate dynamics

In addition to the conceptual basis for expecting reproductive responses to climatic variability, the quantification of such effects has at least two broader implications. First, models of future greenhouse gas emissions tend to focus singularly on how population change influences these emissions (O'Neill et al. 2010; O'Neill et al. 2012), assuming ongoing climatic changes will not in turn influence population dynamics. If such feedback processes exist and they are substantively significant, however, they should be incorporated into demographic models of emissions (Figure 1). Second, changes in fertility may represent an important demographic adaptation to climatic variability, but this outcome has been given much less scholarly attention than other adaptative behaviors (e.g., migration, changes in livelihood; Call et al. 2019; Hunter et 
al. 2015). Evidence of climate-migration links is therefore essential to better understand climatechange adaptation and develop appropriate policy interventions (Yeeles 2018).

\section{Climate exposures and human fertility in Africa}

In this study, we examine the associations between temperature and precipitation variability and fertility across 23 sub-Saharan African countries (Figure 2), using Demographic and Health Survey (DHS) data that span 34 years from 1984 through 2017 (Boyle et al. 2019; see Methods for inclusion criteria). This region is an appropriate and important context for studying such population-environment dynamics. Its environmental and socioeconomic systems are characterized by high levels of vulnerability to ongoing climatic variability and future climate change (De Sherbinin 2014; Thornton et al. 2008). As well, fertility rates across sub-Saharan Africa have been, and remain, much higher than in many other world regions (Bongaarts 2017; Bongaarts \& Casterline 2013). The continent is increasingly important demographically, projected to account for one-third of global population by 2100 (Gerland et al. 2014). Whether and how climatic variability may influence this trajectory therefore has significant implications for development and demography.

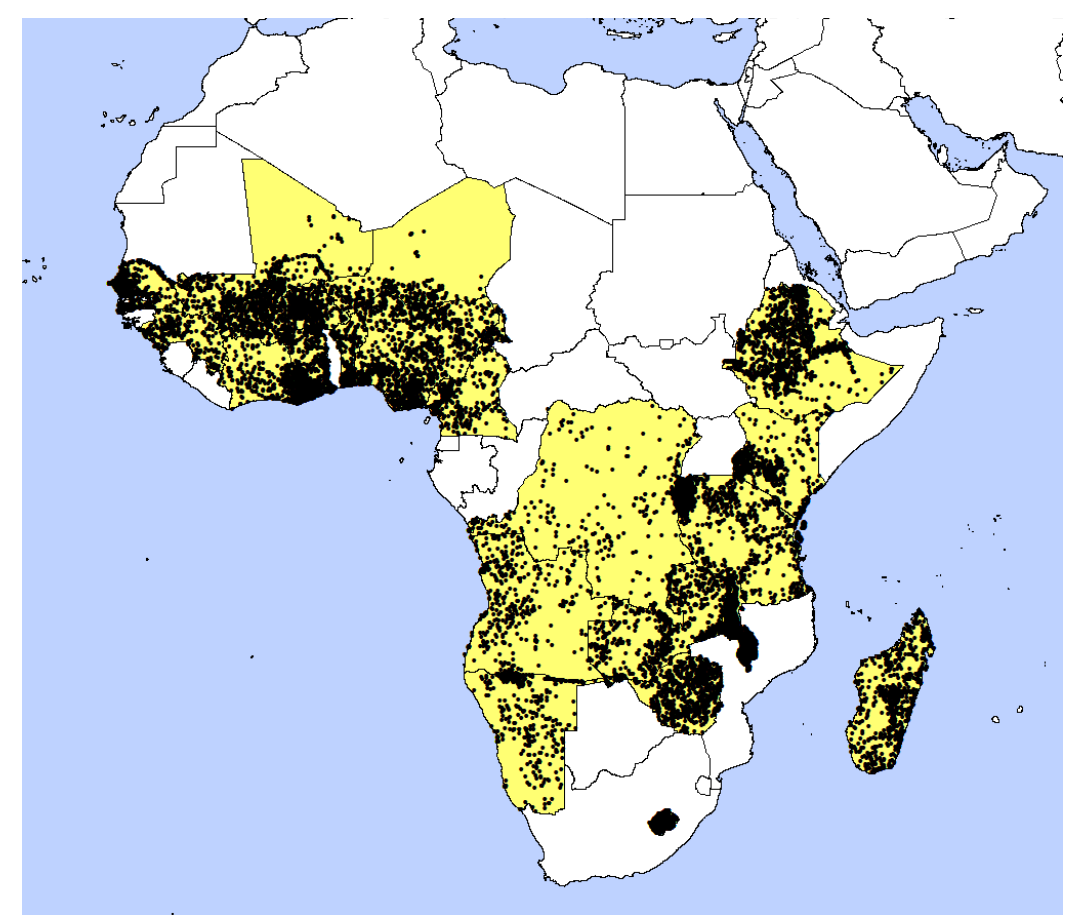

Figure 2: Map of countries and communities included in analytic sample 
Using women's birth records from the DHS, we construct a longitudinal dataset that follows each woman from age 15 through the year of the DHS interview ( $n=4,802,656$ personyears). Our outcome of interest is fertility, which is operationalized as a binary indicator of whether woman $i$ had $1+$ live birth in year $t$. We model fertility as a function of mean temperature and total precipitation during years $t-3$ through $t-1$ (Figure 3 ) and net of controls for possible confounders. Temperature and precipitation measures are derived from high-resolution climate records (Funk et al. 2015; Sheffield 2006) and are measured as spatial means within a 10-kilometer buffer of each community (i.e., cluster) in the DHS. These variables are standardized over the 1981-2014 climate history that is available for each cluster. We include time-varying controls for women's age, first marriage attainment, and children ever born; and time-invariant controls for primary school attainment and residence in a rural or urban community. All models also include linear time trends and province-sample fixed-effects and are estimated using logistic regression. Standard errors are clustered at the DHS cluster level. Results of robustness checks are included in the Supplemental Information (SI).

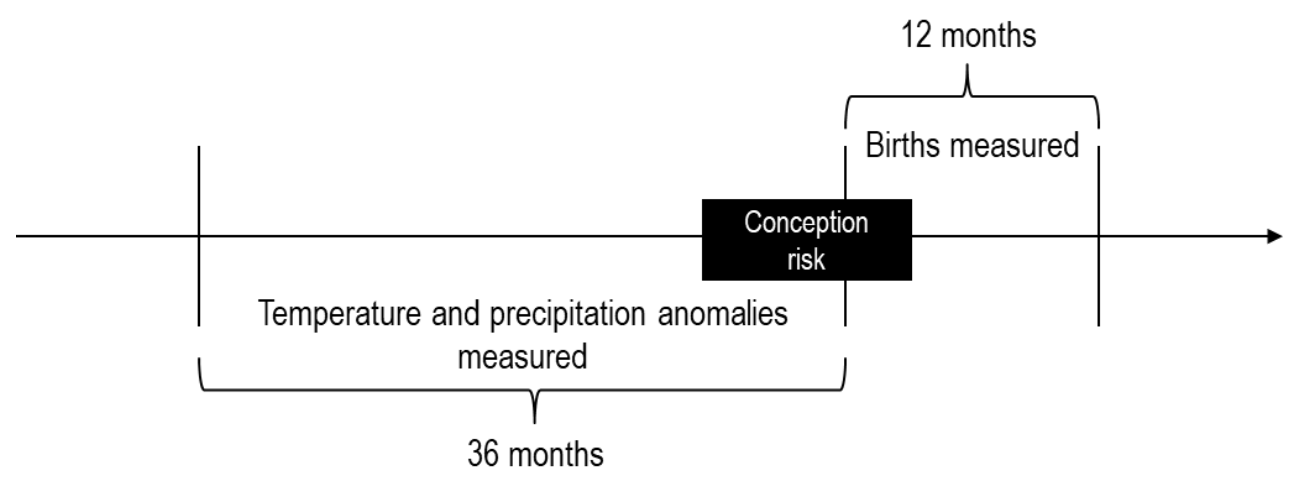

Figure 3: Measurement of dependent and independent variables

We begin by estimating the overall associations between temperature and precipitation variability and the odds of a live birth in a given year, averaged across the entire sample. We estimate specifications with linear, quadratic, and interactive climate terms (Table 1), and our preferred specification allows linear temperature and precipitation terms to interact. We find statistically significant fertility responses to climate anomalies, which vary in direction and magnitude according to the combination of temperature and precipitation anomalies that occur. The biological and socioeconomic impacts of hot-and-dry spells lead to reductions in childbearing: temperature anomalies have a statistically significant negative effect on the annual probability of childbearing when they occur during exceptionally dry periods (marginal effect $=-0.0026, p=$ 
0.000 , when precipitation $\mathrm{z}=-2$ and covariates are held at their means). The predicted probability of fertility in year $t$ decreases from 0.223 during periods of average temperatures and precipitation to 0.213 during hot-and-dry spells (temperature $\mathrm{z}=2$, precipitation $\mathrm{z}=-2$ ) (Figure 4). This temperature effect is moderated and reversed as precipitation increases over baseline. The predicted annual probability of fertility rises to 0.238 when both temperature and precipitation are much above average $(z=2)$. Correspondingly, we observe a statistically significant marginal temperature effect of $0.0044(\mathrm{p}=0.000)$ when precipitation is two standard deviations above normal and other values are held at their means.

Table 1: Logistic regression models of fertility in year $t$

\begin{tabular}{|c|c|c|c|c|c|c|}
\hline & \multicolumn{2}{|l|}{ Model 1} & \multicolumn{2}{|l|}{ Model 2} & \multicolumn{2}{|l|}{ Model 3} \\
\hline Precipitation & $0.0140(0.0016)$ & $* * *$ & $0.0139(0.0016)$ & $* * *$ & $0.0164(0.0016)$ & $* * *$ \\
\hline Precipitation $^{2}$ & & & $-0.0009(0.0011)$ & & & \\
\hline Temperature & $0.0049(0.0020)$ & $* *$ & $0.0042(0.0021)$ & $* *$ & $0.0049(0.0020)$ & $* *$ \\
\hline Temperature $^{2}$ & & & $-0.0015(0.0014)$ & & & \\
\hline Precipitation $\mathrm{x}$ Temperature & & & & & $0.0100(0.0016)$ & $* * *$ \\
\hline Age & $0.2369(0.0016)$ & $* * *$ & $0.2369(0.0016)$ & $* * *$ & $0.2368(0.0016)$ & $* * *$ \\
\hline $\mathrm{Age}^{2}$ & $-0.0048(0.0000)$ & $* * *$ & $-0.0048(0.0000)$ & $* * *$ & $0.0048(0.0000)$ & $* * *$ \\
\hline Ever Married = Yes & $1.9774(0.0067)$ & $* * *$ & $1.9778(0.0067)$ & $* * *$ & $1.9776(0.0067)$ & $* * *$ \\
\hline Primary Education $=$ Yes & $-0.0903(0.0037)$ & $* * *$ & $-0.0909(0.0037)$ & $* * *$ & $-0.0909(0.0037)$ & $* * *$ \\
\hline Cumulative Births & $-0.0062(0.0008)$ & $* * *$ & $-0.0062(0.0009)$ & $* * *$ & $-0.0062(0.0008)$ & $* * *$ \\
\hline Urban Residence & $0.2245(0.0042)$ & $* * *$ & $0.2245(0.0042)$ & $* * *$ & $0.2245(0.0042)$ & $* * *$ \\
\hline Year & $-0.0161(0.0003)$ & $* * *$ & $-0.0161(0.0003)$ & $* * *$ & $-0.0161(0.0003)$ & $* * *$ \\
\hline Sample-Province FE & Yes & & Yes & & Yes & \\
\hline Pseudo $\mathrm{R}^{2}$ & 0.0815 & & 0.0815 & & 0.0815 & \\
\hline Wald $X^{2}$ (df) & $216,313(489)$ & & $216,309(491)$ & & $216,388(490)$ & \\
\hline Sample Size & $4,802,656$ & & $4,802,656$ & & $4,802,656$ & \\
\hline
\end{tabular}

$\dagger \mathrm{p}<0.10 \quad * * \mathrm{p}<0.05 \quad * * * \mathrm{p}<0.001$

Note: Coefficient estimates (standard errors) shown. FE = fixed effects. Precipitation represents the total precipitation during the 36-month period prior to year $t$, standardized over all other 36-month periods in a given community's history. Temperature represents the standardized mean maximum temperature during the same 36 -month period.

Fertility decreases during periods when environmental conditions are least favorable to agricultural production and economic activity but increase during hot-and-rainy periods when agriculture may thrive. Together, these results suggest a dynamic in which households adapt to environment-induced resource constraints by reducing fertility, but conversely seek to increase household size in response to positive shocks. Notably, the magnitude of the estimated effects appears substantively meaningful in many cases: changes in the annual probability of childbearing of just one percentage point may represent 4 to 5 percent of the average annual probability under average conditions. Such a change can also translate into large increases or decreases in the number 
of births when applied to large populations over many decades, as we do in this multi-decade and multi-country study.

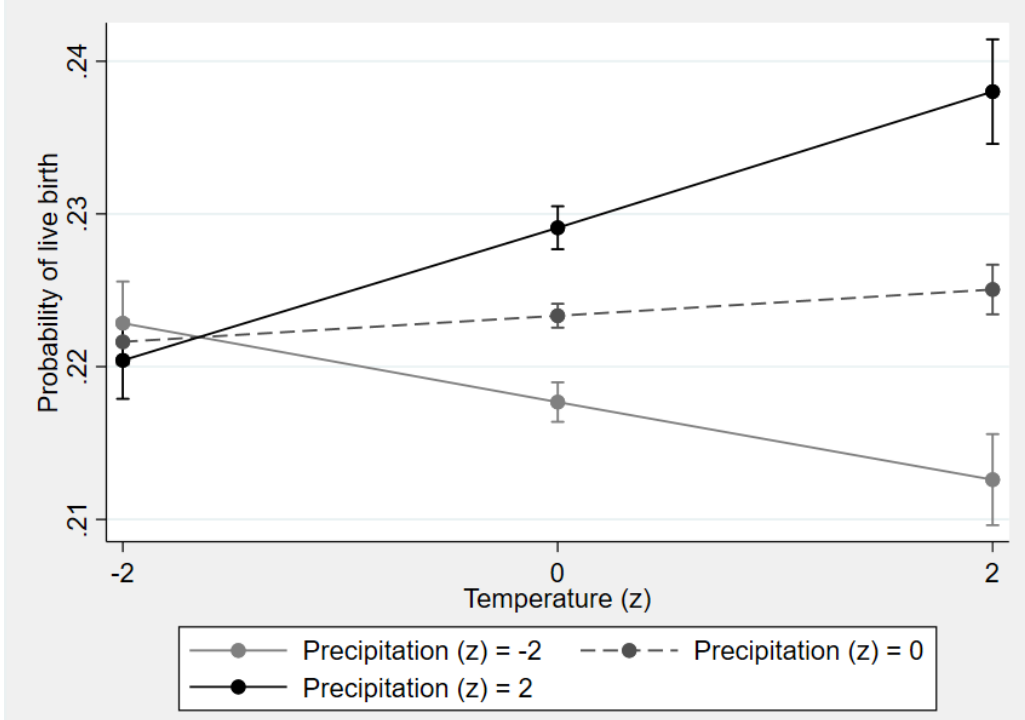

Figure 4: Predicted annual probability (95\% CI) of live birth, by temperature and precipitation (Model 3)

\section{Variation in climate effects across demographic groups}

The impacts of, and demographic responses to, climatic variability are likely to vary across demographic groups and different geographic areas of Africa (Gray \& Wise 2016). Such heterogeneity may reflect systematic differences in vulnerability to shocks, as well as differences in the ability and propensity of women to modify their reproductive behavior as an adaptative strategy (Bohle et al. 1994; Eissler et al. 2019; Sellers \& Gray 2019). As a result of these potentially offsetting dynamics - whereby the most vulnerable may also be least able to adapt - we treat the magnitude and direction of between-group differences as an open question. We address this question by estimating a series of regression models that include climate-by-group interactions, which allow us to compare climate effects between groups. We report group-specific marginal temperature effects across a range of precipitation values in Table 2 (holding all other variables at their means), and a full set of regression estimates in Table A2 in the SI.

We first test for differences in fertility responses according to educational attainment, distinguishing between women with and without a primary school education. Education represents a proxy for socioeconomic status and thus women's ability to buffer against shocks; and it may also be correlated with reproductive decision-making (Behrman 2017). Differences in the overall effects of climate anomalies between these groups are statistically significant $\left(\mathrm{X}^{2}=64.28\right.$, 
$\mathrm{p}=0.000$ ), and the response patterns also vary substantively. Temperature anomalies are positively associated with fertility among both groups of women when they occur during spells of aboveaverage precipitation. During such rainy periods (precipitation $z=2$ ), the respective marginal effects of temperature on the probability of childbearing are 0.006 and 0.004 for women with and without a primary school education. However, temperature anomalies reduce fertility during very dry periods among only women with a primary school education or higher. Under these conditions, the marginal effect of temperature is -0.6 percentage points among such women. While lesseducated women may be expected to be more vulnerable to the impacts of these adverse environmental conditions, they may also be least likely to be able to regulate their fertility. Our results are consistent with the latter dynamic.

Next, we examine the influence of climate anomalies according women's parity at the start of year $t$. The number of children ever born to a woman is expected to be correlated with a range of pertinent factors, including household size, resource constraints, and attainment of fertility preferences (Casterline \& Agyei-Mensah 2017; Desai 1995). Differences in climate effects by parity are also both statistically $\left(\mathrm{X}^{2}=627.89, \mathrm{p}=0.000\right)$ and substantively significant. The response pattern among higher-parity women (e.g., three+ children ever born) is comparable with our overall estimates, with temperature anomalies associated with lower fertility during dry spells but increasing fertility during periods with above-average precipitation. For women at low parities, however, temperature anomalies have a positive influence on fertility across the entire range of plausible precipitation anomalies (e.g., -2 to 2 ).

Third, we test for differences according to marital status given differences in reproductive behavior and decision-making between married and unmarried women (Clark \& Hamplová 2013). Such differences may also be expected if environmental shocks disrupt unmarried women's pathway to marriage and marital childbearing (Jennings \& Gray 2017). The overall difference in climate effects is statistically significant $\left(\mathrm{X}^{2}=40.01, \mathrm{p}=0.000\right)$. However, both ever-married and never-married women exhibit qualitatively similar response patterns to temperature and precipitation anomalies, which is consistent with the overall estimates. Differences between these groups are therefore not substantively important. 
Table 2. Marginal effect of temperature on the annual probability of fertility, by precipitation anomalies

\begin{tabular}{|c|c|c|c|c|}
\hline & \multicolumn{2}{|c|}{ Marginal Effect } & \multicolumn{2}{|c|}{ 95\% Conf. Int. } \\
\hline \multicolumn{5}{|l|}{ Primary Education $=$ No } \\
\hline Precipitation $=-2$ & -0.0004 & & -0.0022 & 0.0013 \\
\hline Precipitation $=0$ & 0.0015 & $* *$ & 0.0006 & 0.0024 \\
\hline Precipitation $=2$ & 0.0035 & $* * *$ & 0.0016 & 0.0054 \\
\hline \multicolumn{5}{|l|}{ Primary Education = Yes } \\
\hline Precipitation $=-2$ & -0.0059 & $* * *$ & -0.0077 & -0.0042 \\
\hline Precipitation $=0$ & 0.0001 & & -0.0008 & 0.0009 \\
\hline Precipitation $=2$ & 0.0061 & $* * *$ & 0.0044 & 0.0079 \\
\hline \multicolumn{5}{|l|}{ Children ever born $=0$} \\
\hline Precipitation $=-2$ & 0.0073 & $* * *$ & 0.0055 & 0.0091 \\
\hline Precipitation $=0$ & 0.0074 & $* * *$ & 0.0065 & 0.0083 \\
\hline Precipitation $=2$ & 0.0075 & $* * *$ & 0.0055 & 0.0094 \\
\hline \multicolumn{5}{|l|}{ Children ever born $=3$} \\
\hline Precipitation $=-2$ & -0.0039 & $* * *$ & -0.0052 & -0.0026 \\
\hline Precipitation $=0$ & 0.0002 & & -0.0005 & 0.0008 \\
\hline Precipitation $=2$ & 0.0044 & $* * *$ & 0.0031 & 0.0057 \\
\hline \multicolumn{5}{|l|}{ Children ever born $=6$} \\
\hline Precipitation $=-2$ & -0.0152 & $* * *$ & -0.0173 & -0.0132 \\
\hline Precipitation $=0$ & -0.0069 & $* * *$ & -0.0078 & -0.0059 \\
\hline Precipitation $=2$ & 0.0015 & & -0.0006 & 0.0036 \\
\hline \multicolumn{5}{|l|}{ Ever married $=0$} \\
\hline Precipitation $=-2$ & -0.0036 & $* * *$ & -0.0049 & -0.0022 \\
\hline Precipitation $=0$ & 0.0012 & $* * *$ & 0.0005 & 0.0019 \\
\hline Precipitation $=2$ & 0.0065 & $* * *$ & 0.0048 & 0.0082 \\
\hline \multicolumn{5}{|l|}{ Ever married $=1$} \\
\hline Precipitation $=-2$ & -0.0024 & $* *$ & -0.0040 & -0.0008 \\
\hline Precipitation $=0$ & 0.0008 & $* *$ & 0.0000 & 0.0016 \\
\hline Precipitation $=2$ & 0.0041 & $* * *$ & 0.0025 & 0.0058 \\
\hline \multicolumn{5}{|l|}{ Urban } \\
\hline Precipitation $=-2$ & -0.0100 & $* * *$ & -0.0124 & -0.0077 \\
\hline Precipitation $=0$ & -0.0024 & $* * *$ & -0.0035 & -0.0013 \\
\hline Precipitation $=2$ & 0.0052 & $* * *$ & 0.0027 & 0.0077 \\
\hline \multicolumn{5}{|l|}{ Rural } \\
\hline Precipitation $=-2$ & -0.0001 & & -0.0015 & 0.0014 \\
\hline Precipitation $=0$ & 0.0022 & $* * *$ & 0.0014 & 0.0029 \\
\hline Precipitation $=2$ & 0.0045 & $* * *$ & 0.0030 & 0.0060 \\
\hline \multicolumn{5}{|c|}{$\begin{array}{l}\dagger \mathrm{p}<0.10 \quad * * \mathrm{p}<0.05 \quad * * * \mathrm{p}<0.001 \\
\text { Note: results of two-sided statistical tests shown. Marginal effects by education are derived } \\
\text { from a model with climate-by-education interactions (Model } 4 \text { in the } \mathrm{SI} \text { ). Marginal effects by } \\
\text { parity are derived from a model with climate-by-parity interactions (Model } 5 \text { in the SI). } \\
\text { Marginal effects by marital status are derived from a model with climate-by-marital status } \\
\text { interactions (Model } 6 \text { in the SI). Marginal effects by rural/urban residence are derived from a } \\
\text { model with climate-by-residence type interactions (Model } 7 \text { in the SI). The sample size for all } \\
\text { models is } 4,802,656 \text { person-years. }\end{array}$} \\
\hline
\end{tabular}


Finally, we compare fertility responses to climate anomalies between rural and urban areas, where living standards and reproductive outcomes differ considerably (Sahn \& Stifel 2003). Our results reveal statistically significant rural-urban differences in climate effects overall $\left(\mathrm{X}^{2}=128.21\right.$, $\mathrm{p}=0.000$ ). Responses among urban women are broadly consistent with the main results and suggest substantively meaningful temperature and precipitation effects in urban areas. For example, temperature anomalies are associated with a full 1.0-point marginal reduction in the probability of fertility in urban areas when they occur during very dry spells, and with a 0.5-point marginal increase when they occur during rainy periods. A similar change occurs during rainy spells in rural areas, when and where temperature has a marginal effect of 0.4 percentage points. However, temperature anomalies have null effects during dry spells in such places. This set of results undermines the common but wrongly-held assumption that rural populations are uniformly most vulnerable to climate change (Desbureaux \& Rodella 2019). It also raises questions about rural women's ability to reduce fertility in the face of resource constraints, which may be limited due to poor access to contraceptives or pronatalist social norms (White et al. 2008).

\section{Country-specific climate effects}

As a final analysis, we estimate a series of county-stratified models, which are specified similarly to our models using the pooled sample. Our goal here is not to formally test for differences between countries, but to illustrate the range in magnitude and direction of fertility responses to climatic variability across the region. To do so, we display the marginal effects of temperature anomalies on the annual probability of childbearing during both dry (Panel A), precipitation $\mathrm{z}=-2$ ) and rainy (Panel B, precipitation $\mathrm{z}=2$ ) periods (Figure A). The marginal effects of temperature for both dry and rainy periods vary considerably across the countries in our sample. However, these stratified models suggest that many countries experience climate-induced changes in fertility that are consistent with our pooled estimates. A plurality of countries where characterized by positive temperature effects during rainy periods and the reverse is true for dry periods. The results also demonstrate that the estimates from the main model were not driven by the experience of a single country. 

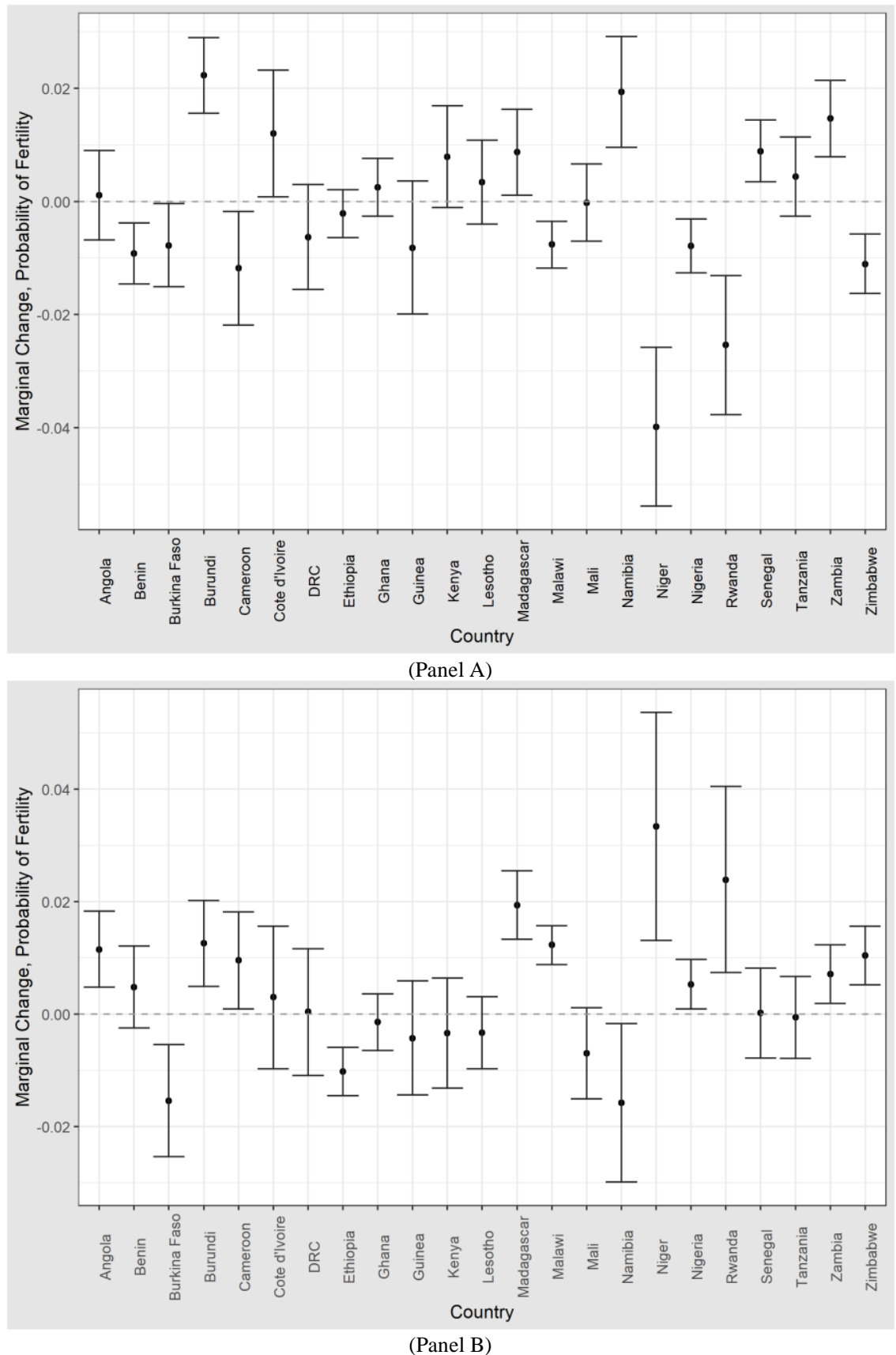

Figure 5: Marginal effect ( $95 \%$ CI) of temperature on annual probability of live birth, low-precipitation (panel A) and high-precipitation (panel B) scenarios

\section{Family planning, population policy, and climate change adaptation}

Our analysis of DHS data from sub-Saharan Africa shows that birth rates are robustly associated with women's recent exposure to climate variability. Women exposed to above-average temperatures and below-average precipitation during a given 36-month period are significantly less like to experience a live birth in the subsequent year than comparable women exposed to the 
average conditions for their locality. Conversely, hot-and-rainy spells were associated with significant increases in birth rates during the following year. This set of findings is consistent with a dynamic in which households reduce fertility (and thus limit household size) in response to adverse environmental conditions and their second-order socioeconomic and epidemiological impacts, but increase fertility over baseline levels in response to favorable conditions. As such, these findings run contrary to the so-called vicious circle model, which predicts an increased demand for children (and their labor) under environmental constraints (Filmer \& Pritchett 2002).

This headline finding should be interpreted in the context of three additional points. First, temperature and precipitation shocks on the order of $z=|2|$ lead to changes in the annual probability of fertility of approximately 1.0-1.5 percentage points, or 4.5-6.7 percent of the baseline probability. Such effects are substantively important on their own terms and may translate into an absolutely large number of additional (fewer) births in a given year across the large population our data are representative of. Second and relatedly, this analysis focus on changes in the annual probability of childbearing and therefore cannot distinguish between climatic influences on the timing of childbearing (i.e., a birth in year $t$ relative to $t+1$ ) versus the total number of children ever born (i.e., tempo vs. quantum effects; Bongaarts \& Feeney 1998). It is possible that reductions (increases) in fertility during year $t$ are partially offset by an increased (decreased) likelihood of childbearing in subsequent years. Third, the strength and direction of climate effects varies significantly across multiple sub-populations, including by education, parity, marital status, and rural (or urban) residence. These effects also vary across a number of the 23 countries in our sample. We detect a strong climate signal across many of these sub-populations, and in many cases these group-specific estimates correspond to the overall, average estimates. However, evidence of heterogeneity underscores the need to consider the socioeconomic and environmental conditions that may moderate climate-fertility linkages.

Our results have at least two major implications for the broader literate on human population dynamics and climate change. First, they clearly demonstrate that human fertility patterns are sensitive to climatic variability (Grace 2017). This evidence underscores the need to account for feedbacks between climate dynamics and birth rates when modeling the demographic determinants of greenhouse gas emissions (O’Neill et al. 2010; O’Neill et al. 2012). For example, to the extent that anthropogenic climate change leads to increased frequency of hot-and-dry spells across sub-Saharan Africa, household responses will offset rather than amplify population growth 
according to our study. Second, evidence of reproductive responses to climatic variability demonstrates the need to consider a full repertoire of adaptive behaviors that households may employ in response to changing environmental conditions (i.e., multiphasic responses; Friedlander 1969). Social scientists and policymakers have focused disproportionately on the links between climate variability and migration to date (Hunter et al. 2015; Rigaud et al. 2018). Renewed attention to the other ways that households modify their size and structure in response to shocksas well as how these various behaviors are related-is needed to better-understand in and ex situ adaptive behaviors. It is also needed to design appropriate interventions that facilitate successful adaptations to ongoing climatic variability and future climate change (Yeeles 2018).

\section{Methods}

We analyze retrospective birth records from Demographic and Health Surveys (DHS) implemented in 23 sub-Saharan African countries. Our dataset includes all DHS samples currently available through IPUMS-DHS and for which publicly available geocoordinates allowed for linkages with temperature and precipitation records. We further restrict the dataset to include samples that collected information on time in current residence, which allows us to exclude personyears that occurred in previous (unobservable) residences. Using these data, we then construct a person-year dataset that follows each woman from age 15 through the year of the DHS interview $(\mathrm{n}=4,802,656)$.

Our outcome of interest is fertility in year $t$, which is operationalized as a binary indicator of whether 1+ live birth occurred in that year. We estimate pooled logistic regression models of fertility as a function of mean maximum temperature and total precipitation during years t-3 through t-1 net of controls. Temperature and precipitation measures are derived from highresolution climate records (Funk et al. 2015; Sheffield 2006) and are measured as spatial means within a 10-kilometer buffer of each community (i.e., cluster) in the DHS, as performed by IPUMS-DHS (Boyle et la. 2019). These variables are standardized over the 1981-2014 climate history for each DHS cluster, and can therefore be interpreted as cluster-specific z-scores. The models include time-varying controls for women's age, first marriage attainment, and children ever born, and time-invariant controls for primary school attainment and residence in a rural or urban community. All models control for linear time trends and province-sample fixed-effects, and standard errors are clustered at the DHS cluster level. The first three models (Models 1-3, 
Table 1) estimate average climate effects across the entire sample. Models 4-7 (Table A2 in the SI) include a series of climate-by-group interaction terms to test for differences in the effects of climate exposures on fertility across sub-populations. Finally, we estimate country-stratified models to identify the unique effects of climate exposure across the 23 countries in our sample (Figure 5).

With the exception of the country-stratified analyses, all models are estimated across the pooled sample of 4,802,656 person-year observations. The sample size for the country-specific models are as follows: Angola $(177,218)$, Benin $(94,132)$, Burkina Faso $(216,600)$, Burundi $(179,139)$, Cameroon $(105,658)$, Congo Democratic Republic $(104,218)$, Cote d'Ivoire $(48,987)$, Ethiopia (481,226), Ghana $(163,290)$, Guinea $(91,250)$, Kenya $(137,836)$, Lesotho $(127,270)$, Madagascar (115,264), Malawi (687,260), Mali (358,278), Namibia (138,797), Niger (104,218), Nigeria (426,476), Rwanda (95,573), Senegal (237,251), Tanzania (175,777), Zambia (191,146), and Zimbabwe $(209,396)$. All p-values and test statistics reported in the text and SI reflect the results of two-sided tests. Robustness checks using alternative climate exposure periods and clustering standard errors on the sample-province were performed and reported in the SI (Table A3). 


\section{References}

Agadjanian, V., Yabiku, S. T., \& Cau, B. (2011). Men's migration and women's fertility in rural Mozambique. Demography, 48(3), 1029-1048.

Alam, S. A., \& Pörtner, C. C. (2018). Income shocks, contraceptive use, and timing of fertility. Journal of Development Economics, 131, 96-103.

Behrman, J. A. (2017). Women's land ownership and participation in decision-making about reproductive health in Malawi. Population and Environment, 38(4), 327-344.

Bohle, H. G., Downing, T. E., \& Watts, M. J. (1994). Climate change and social vulnerability: toward a sociology and geography of food insecurity. Global Environmental Change, 4(1), 3748.

Bongaarts, J. (1992). Population growth and global warming. Population and Development Review, 299-319.

Bongaarts, J. (2017). Africa's unique fertility transition. Population and Development Review, $43,39-58$.

Bongaarts, J., \& Feeney, G. (1998). On the quantum and tempo of fertility. Population and Development Review, 271-291.

Bongaarts, J., \& O'Neill, B. C. (2018). Global warming policy: Is population left out in the cold? Science, 361(6403), 650-652.

Boyle, E. H., King, M., \& Sobek, M. (2019). IPUMS-Demographic and Health Surveys: Version 7 [dataset]. Minnesota Population Center and ICF International.

Call, M., Gray, C., \& Jagger, P. (2019). Smallholder responses to climate anomalies in rural Uganda. World Development, 115, 132-144.

Casterline, J. B., \& Agyei-Mensah, S. (2017). Fertility desires and the course of fertility decline in sub-Saharan Africa. Population and Development Review, 43, 84-111.

Clark, S., \& Hamplová, D. (2013). Single motherhood and child mortality in sub-Saharan Africa: A life course perspective. Demography, 50(5), 1521-1549.

Davenport, F., Dorélien, A., \& Grace, K. (2020). Investigating the linkages between pregnancy outcomes and climate in sub-Saharan Africa. Population and Environment, 1-25.

Dercon, S., Hoddinott, J., \& Woldehanna, T. (2005). Shocks and consumption in 15 Ethiopian villages, 1999-2004. Journal of African Economies, 14(4), 559. 
Desai, S. (1995). When are children from large families disadvantaged? Evidence from crossnational analyses. Population Studies, 49(2), 195-210.

Desbureaux, S., \& Rodella, A. S. (2019). Drought in the city: The economic impact of water scarcity in Latin American metropolitan areas. World Development, 114, 13-27.

De Sherbinin, A. (2014). Climate change hotspots mapping: what have we learned?. Climatic Change, 123(1), 23-37.

Eissler, S., Thiede, B. C., \& Strube, J. (2019). Climatic variability and changing reproductive goals in Sub-Saharan Africa. Global Environmental Change, 57, 101912.

Filmer, D., \& Pritchett, L. H. (2002). Environmental degradation and the demand for children: searching for the vicious circle in Pakistan. Environment and Development Economics, 7(1), 123-146.

Friedlander, D. (1969). Demographic responses and population change. Demography, 6(4), 359381.

Funk, C., Peterson, P., Landsfeld, M., Pedreros, D., Verdin, J., Shukla, S., ... \& Michaelsen, J. (2015). The climate hazards infrared precipitation with stations - a new environmental record for monitoring extremes. Scientific Data, 2(1), 1-21.

Grace, K. (2017). Considering climate in studies of fertility and reproductive health in poor countries. Nature Climate Change, 7(7), 479-485.

Gray, C., \& Wise, E. (2016). Country-specific effects of climate variability on human migration. Climatic Change, 135(3-4), 555-568.

Hertel, T. W., Burke, M. B., \& Lobell, D. B. (2010). The poverty implications of climateinduced crop yield changes by 2030. Global Environmental Change, 20(4), 577-585.

Hidrobo, M., \& Fernald, L. (2013). Cash transfers and domestic violence. Journal of Health Economics, 32(1), 304-319.

Hidrobo, M., Peterman, A., \& Heise, L. (2016). The effect of cash, vouchers, and food transfers on intimate partner violence: evidence from a randomized experiment in Northern Ecuador. American Economic Journal: Applied Economics, 8(3), 284-303.

Hunter, L. M., Luna, J. K., \& Norton, R. M. (2015). Environmental dimensions of migration. Annual Review of Sociology, 41, 377-397.

Jennings, J. A., \& Gray, C. L. (2017). Climate and Marriage in the Netherlands, 1871-1937. Population and Environment, 38(3), 242-260. 
Lutz, W. (2017). How population growth relates to climate change. Proceedings of the National Academy of Sciences, 114(46), 12103-12105.

McKelvey, C., Thomas, D., \& Frankenberg, E. (2012). Fertility regulation in an economic crisis. Economic Development and Cultural Change, 61(1), 7-38.

Mueller, V., Gray, C., \& Kosec, K. (2014). Heat stress increases long-term human migration in rural Pakistan. Nature Climate Change, 4(3), 182-185.

Nawrotzki, R. J., Riosmena, F., Hunter, L. M., \& Runfola, D. M. (2015). Amplification or suppression: Social networks and the climate change-migration association in rural Mexico. Global Environmental Change, 35, 463-474.

Nobles, J., Frankenberg, E., \& Thomas, D. (2015). The effects of mortality on fertility: population dynamics after a natural disaster. Demography, 52(1), 15-38.

O’Neill, B. C., Dalton, M., Fuchs, R., Jiang, L., Pachauri, S., \& Zigova, K. (2010). Global demographic trends and future carbon emissions. Proceedings of the National Academy of Sciences, 107(41), 17521-17526.

O’Neill, B. C., Liddle, B., Jiang, L., Smith, K. R., Pachauri, S., Dalton, M., \& Fuchs, R. (2012). Demographic change and carbon dioxide emissions. The Lancet, 380(9837), 157-164.

Rigaud, Kanta Kumari, Alex de Sherbinin, Bryan Jones, Jonas Bergmann, Viviane Clement, Kayly Ober, Jacob Schewe et al. (2018). Groundswell. World Bank.

Sahn, D. E., \& Stifel, D. C. (2003). Urban-rural inequality in living standards in Africa. Journal of African Economies, 12(4), 564-597.

Sellers, S., \& Gray, C. (2019). Climate shocks constrain human fertility in Indonesia. World Development, 117, 357-369.

Sheffield, J., Goteti, G., \& Wood, E. F. (2006). Development of a 50-year high-resolution global dataset of meteorological forcings for land surface modeling. Journal of Climate, 19(13), 30883111.

Thornton, P. K., Jones, P. G., Owiyo, T., Kruska, R. L., Herrero, M., Orindi, V., ... \& Omolo, A. (2008). Climate change and poverty in Africa: Mapping hotspots of vulnerability. African Journal of Agricultural and Resource Economics, 2(311-2016-5524), 24-44.

White, M. J., Muhidin, S., Andrzejewski, C., Tagoe, E., Knight, R., \& Reed, H. (2008).

Urbanization and fertility: An event-history analysis of coastal Ghana. Demography, 45(4), 803816.

Yeeles, A. (2018). Mainstreaming adaptation. Nature Climate Change, 8(2), 95-95. 


\section{Supplemental Information}

Table A1: Descriptive Statistics

\begin{tabular}{|c|c|c|c|c|}
\hline & Mean & SD & Min & Max \\
\hline Birth in Year $t$ & 0.2115 & - & 0 & 1 \\
\hline Age & 26.2204 & 7.8158 & 15 & 45 \\
\hline Ever Married in Year $t$ & 0.7957 & - & 0 & 1 \\
\hline Cumulative Births & 2.5371 & 2.5806 & 0 & 19 \\
\hline \multicolumn{5}{|l|}{ Place of Residence } \\
\hline Urban & 0.2712 & - & 0 & 1 \\
\hline Rural & 0.7288 & - & 0 & 1 \\
\hline Year & 1998.7350 & 8.0235 & 1984 & 2017 \\
\hline \multicolumn{5}{|l|}{ Country } \\
\hline Angola & 0.0369 & - & 0 & 1 \\
\hline Burundi & 0.0373 & - & 0 & 1 \\
\hline Burkina Faso & 0.0451 & - & 0 & 1 \\
\hline Cameroon & 0.022 & - & 0 & 1 \\
\hline Congo Democratic Republic & 0.0217 & - & 0 & 1 \\
\hline Cote d'Ivoire & 0.0102 & - & 0 & 1 \\
\hline Benin & 0.0196 & - & 0 & 1 \\
\hline Ethiopia & 0.1002 & - & 0 & 1 \\
\hline Ghana & 0.03400 & - & 0 & 1 \\
\hline Guinea & 0.01900 & - & 0 & 1 \\
\hline Kenya & 0.0287 & - & 0 & 1 \\
\hline Lesotho & 0.0265 & - & 0 & 1 \\
\hline Madagascar & 0.0240 & - & 0 & 1 \\
\hline Malawi & 0.1431 & - & 0 & 1 \\
\hline Mali & 0.0746 & - & 0 & 1 \\
\hline Namibia & 0.0289 & - & 0 & 1 \\
\hline Niger & 0.0217 & - & 0 & 1 \\
\hline Nigeria & 0.0888 & - & 0 & 1 \\
\hline Rwanda & 0.0199 & - & 0 & 1 \\
\hline Senegal & 0.0494 & - & 0 & 1 \\
\hline Tanzania & 0.0366 & - & 0 & 1 \\
\hline Zambia & 0.0398 & - & 0 & 1 \\
\hline Zimbabwe & 0.0436 & - & 0 & 1 \\
\hline
\end{tabular}


Table A2: Logistic Regression Models of Fertility in Year $t$, with Interactions

\begin{tabular}{|c|c|c|c|c|c|c|c|c|}
\hline & Model 4 & & Model 5 & & Model 6 & & Model 7 & \\
\hline Precipitation & $0.0238(0.0023)$ & $* * *$ & $0.0281(0.0024)$ & $* * *$ & $0.0336(0.0063)$ & $* * *$ & $0.0014(0.0035)$ & \\
\hline Temperature & $0.0083(0.0025)$ & $* * *$ & $0.0423(0.0026)$ & $* * *$ & $0.0228(0.0064)$ & $* * *$ & $-0.0153(0.0036)$ & $* * *$ \\
\hline Precipitation $\mathrm{x}$ Temperature & $0.0054(0.0023)$ & $* *$ & $-0.0005(0.0024)$ & & $0.0465(0.0066)$ & $* * *$ & $0.0242(0.0036)$ & $* * *$ \\
\hline Primary Education $\mathrm{x}$ Precipitation & $-0.0159(0.0031)$ & $* * *$ & & & & & & \\
\hline Primary Education $\mathrm{x}$ Temperature & $-0.0078(0.0031)$ & $* *$ & & & & & & \\
\hline Primary Education $\mathrm{x}$ Precipitation $\mathrm{x}$ Temperature & $0.0123(0.0032)$ & $* * *$ & & & & & & \\
\hline Cumulative Births $\mathrm{x}$ Precipitation & & & $-0.0047(0.0007)$ & $* * *$ & & & & \\
\hline Cumulative Births x Temperature & & & $-0.0138(0.0006)$ & $* * *$ & & & & \\
\hline Cumulative Births $\mathrm{x}$ Precipitation $\mathrm{x}$ Temperature & & & $0.0042(0.0007)$ & $* * *$ & & & & \\
\hline Ever Married x Precipitation & & & & & $-0.0182(0.0065)$ & $* *$ & & \\
\hline Ever Married x Temperature & & & & & $-0.0189(0.0064)$ & $* *$ & & \\
\hline Ever Married x Precipitation x Temperature & & & & & $-0.0387(0.0068)$ & $* * *$ & & \\
\hline Urban x Precipitation & & & & & & & $0.0192(0.0038)$ & $* * *$ \\
\hline Urban x Temperature & & & & & & & $0.0274(0.0038)$ & $* * *$ \\
\hline Urban $\mathrm{x}$ Precipitation $\mathrm{x}$ Temperature & & & & & & & $-0.0180(0.0039)$ & $* * *$ \\
\hline Age & $0.2370(0.0016)$ & $* * *$ & $0.2340(0.0016)$ & $* * *$ & $0.2368(0.0016)$ & $* * *$ & $0.2370(0.0016)$ & $* * *$ \\
\hline $\mathrm{Age}^{2}$ & $-0.0048(0.0000)$ & $* * *$ & $-0.0047(0.0000)$ & $* * *$ & $-0.0048(0.0000)$ & $* * *$ & $-0.0048(0.0000)$ & $* * *$ \\
\hline Ever Married = Yes & $1.9778(0.0067)$ & $* * *$ & $1.9849(0.0068)$ & $* * *$ & $1.9739(0.0068)$ & $* * *$ & $1.9776(0.0067)$ & $* * *$ \\
\hline Primary Education $=$ Yes & $-0.0923(0.0038)$ & $* * *$ & $-0.0920(0.0037)$ & $* * *$ & $-0.0911(0.0037)$ & $* * *$ & $-0.0912(0.0037)$ & $* * *$ \\
\hline Cumulative Births & $-0.0063(0.0009)$ & $* * *$ & $-0.0102(0.0009)$ & $* * *$ & $-0.0062(0.0009)$ & $* * *$ & $-0.0064(0.0009)$ & $* * *$ \\
\hline Urban Residence & $0.2247(0.0042)$ & $* * *$ & $0.2258(0.0042)$ & $* * *$ & $0.2246(0.0042)$ & $* * *$ & $0.2307(0.0043)$ & $* * *$ \\
\hline Year & $-0.0162(0.00003)$ & $* * *$ & $-0.0164(0.0003)$ & $* * *$ & $-0.0161(0.0003)$ & $* * *$ & $-0.0162(0.0003)$ & $* * *$ \\
\hline Sample-Province Fixed Effects & Yes & & Yes & & Yes & & Yes & \\
\hline Pseudo $R^{2}$ & 0.0815 & & 0.0817 & & 0.0815 & & 0.0815 & \\
\hline Wald $X^{2}(\mathrm{df})$ & $216,353(493)$ & & $216,553(493)$ & & $216,411(493)$ & & $216,226(493)$ & \\
\hline Sample Size & $4,802,656$ & & $4,802,656$ & & $4,802,656$ & & $4,802,656$ & \\
\hline
\end{tabular}

†p $<0.10 \quad * * \mathrm{p}<0.05 \quad * * * \mathrm{p}<0.001$

Note: Coefficient estimates (standard errors) shown. Precipitation represents the total precipitation during the 36 -month period prior to year $t$, standardized over all other 36-month periods in a given community's history. Temperature represents the standardized mean maximum temperature during the same 36-month period. 
Table A3: Logistic Regression Models of Fertility in Year $t$, Alternative Specifications

\begin{tabular}{|c|c|c|c|c|c|c|}
\hline \multirow[b]{3}{*}{ Precipitation } & \multicolumn{2}{|l|}{ Model 8} & \multicolumn{2}{|l|}{ Model 9} & \multicolumn{2}{|l|}{ Model 10} \\
\hline & \multicolumn{2}{|c|}{$\begin{array}{l}\text { 2-year climate } \\
\text { exposures }\end{array}$} & \multicolumn{2}{|l|}{$\begin{array}{l}\text { 4-year climate } \\
\text { exposures }\end{array}$} & \multicolumn{2}{|c|}{$\begin{array}{c}\text { Standard errors } \\
\text { clustered on sample- } \\
\text { province units }\end{array}$} \\
\hline & $0.0146(0.0016)$ & $* * *$ & $0.0085(0.0017)$ & $* * *$ & $0.0173(0.0017)$ & $* * *$ \\
\hline Temperature & $0.0089(0.0018)$ & $* * *$ & $0.0003(0.0021)$ & & $0.0066(0.0020)$ & $* *$ \\
\hline Precipitation' x Temperature & $0.0073(0.0016)$ & $* * *$ & $-0.0001(0.0017)$ & & $0.0094(0.0017)$ & $* * *$ \\
\hline Age & $0.2373(0.0016)$ & $* * *$ & $0.2359(0.0016)$ & $* * *$ & $0.1951(0.0016)$ & $* * *$ \\
\hline $\operatorname{Age}^{2}$ & $-0.0048(0.0000)$ & $* * *$ & $-0.0048(0.0000)$ & $* * *$ & $-0.0041(0.0000)$ & $* * *$ \\
\hline Ever Married = Yes & $1.9801(0.0067)$ & $* * *$ & $1.9779(0.0068)$ & $* * *$ & - & \\
\hline Primary Education $=$ Yes & $-0.0900(0.0037)$ & $* * *$ & $-0.0048(0.0038)$ & $* * *$ & $-0.0732(0.0038)$ & $* * *$ \\
\hline Cumulative Births & $-0.0058(0.0008)$ & $* * *$ & $-0.0069(0.0009)$ & $* * *$ & $-0.0060(0.0009)$ & $* * *$ \\
\hline Urban Residence & $0.2210(0.0042)$ & $* * *$ & $0.2280(0.0043)$ & $* * *$ & $0.2225(0.0044)$ & $* * *$ \\
\hline Year & $-0.0157(0.0003)$ & $* * *$ & $-0.0162(0.0003)$ & $* * *$ & $-0.0155(0.0003)$ & $* * *$ \\
\hline Sample-Province Fixed Effects & Yes & & Yes & & Yes & \\
\hline Pseudo $\mathrm{R}^{2}$ & 0.0813 & & 0.0816 & & 0.0309 & \\
\hline Wald $X^{2}(\mathrm{df})$ & $220,018(490)$ & & $212,424(490)$ & & 88,423 (489) & \\
\hline Sample Size & $4,886,857$ & & $4,710,079$ & & $3,810,005$ & \\
\hline
\end{tabular}

$\dagger \mathrm{p}<0.10 \quad * * \mathrm{p}<0.05 \quad * * * \mathrm{p}<0.001$

Note: Coefficient estimates (standard errors) shown. 2-year climate exposures include the years $t-2$ and $t-1$, and 4-year climate exposures include the years $t-4$ through $t-1$. 